\title{
THE BIOSYNTHESIS OF BROMINATED PYRROLNITRIN DERIVATIVES BY PSEUDOMONAS AUREOFACIENS
}

\author{
Karl-Heinz van Pée, Olga Salcher, Peter Fischer*, \\ Michael BoKel** and Franz LingenS \\ Institut für Mikrobiologie der Universität Hohenheim, \\ Garbenstrasse 30, D-7000 Stuttgart 70, Germany \\ *Institut für Organische Chemie Biochemie und Isotopenforschung der Universität Stuttgart \\ Pfaffenwaldring 55, D-7000 Stuttgart, Germany \\ **Institut für Chemie der Universität Hohenheim, \\ Garbenstrasse 30, D-7000 Stuttgart 70, Germany
}

(Received for publication August 31, 1983)

\begin{abstract}
The mutant strain ACN of Pseudomonas aureofaciens ATCC 15926 produces several bromo derivatives of pyrrolnitrin. Five brominated amino- and three brominated nitrophenyl pyrrole compounds could be isolated, and their structures were established by ${ }^{1} \mathrm{H}$ NMR, UV and mass spectroscopy. The isolated amino compounds showed no biological activity; the nitro derivatives inhibited the growth of Neurospora crassa ATCC 9276, though not as effective as pyrrolnitrin itself. 2-Carboxy-4-(2-amino-3-bromophenyl)pyrrole (X) is demonstrated to be an intermediate in the biosynthesis of brominated pyrrolnitrin; the biosynthetic pathway to bromo derivatives of pyrrolnitrin is discussed.
\end{abstract}

In 1965, the potent antifungal antibiotic pyrrolnitrin (I) (3-chloro-4-(2-nitro-3-chlorophenyl)pyrrole)* was isolated from Pseudomonas pyrrocinia ${ }^{1}$. Since then, several other Pseudomonas sp. have been found to produce $\mathbf{I}^{2)}$, and a number of pyrrolnitrin derivatives have been isolated by different groups ${ }^{3)}$. HAMILL et al $^{4}{ }^{4}$ reported that in the presence of ammonium bromide no brominated pyrrolnitrin derivatives were produced by $P$. aureofaciens. However, P. pyrrolnitrica, P. pyrrocinia, and P. schuylkilliensis were found to synthesize three brominated nitrophenyl pyrrole compounds. ${ }^{5)}$ It therefore appeared probable that bromophenyl pyrrole compounds could be isolated from $P$. aureofaciens too. At the same time we thought it possible, by employing the bromo analogue (X), to establish 2-carboxy-4-(2amino-3-chlorophenyl)pyrrole ${ }^{6)}$ as either a precursor of pyrrolnitrin or a deadend product ${ }^{3)}$. As a part of our continuing efforts to unravel the biosynthesis of pyrrolnitrin, the present paper details the isolation and structural elucidation of several new brominated pyrrolnitrin derivatives.

\section{Materials and Methods}

Organism and Culture Conditions

P. aureofaciens ATCC 15926 (mutant strain $\mathrm{ACN}$ ) ${ }^{7}$ was grown at $30^{\circ} \mathrm{C}$ with 3 liters/minute aeration and stirring in 10- and 30-liter fermenters for 96 hours. The mineral salt medium used was: glycerol $30 \mathrm{~g},\left(\mathrm{NH}_{4}\right)_{2} \mathrm{SO}_{4} 1 \mathrm{~g}, \mathrm{NaBr} 5 \mathrm{~g}, \mathrm{MgSO}_{4} \cdot 7 \mathrm{H}_{2} \mathrm{O} 0.5 \mathrm{~g}, \mathrm{~K}_{2} \mathrm{HPO}_{4} 3 \mathrm{~g}, \mathrm{KH}_{2} \mathrm{PO}_{4} 0.5 \mathrm{~g}$, D-tryptophan $0.61 \mathrm{~g}$ and deionized water to 1 liter, $\mathrm{pH} 7$.

The antibiotic activity of the bromopyrrolnitrin derivatives was determined by the agar-well diffusion technique, with Neurospora crassa ATCC 9276 as the test organism ${ }^{8}$.

Isolation of Brominated Pyrrolnitrin Derivatives

After 4 days of incubation, the cell-free medium was concentrated in vacuo to one-tenth the original

* As a matter of convenience we use the pyrrolnitrin numbering system for all the phenylpyrroles described in this paper. 
volume, brought to $\mathrm{pH} 5.5$, and then extracted with 2 volumes of ethyl acetate. The cells were extracted with aqueous acetone, the resulting solution concentrated to remove acetone, and extracted with ethyl acetate. The combined extracts were dried over anhydrous $\mathrm{MgSO}_{4}$ and evaporated to dryness. The residue was dissolved in as little methanol as possible, applied to a Sephadex LH-20 column, and developed with methanol. This separated amino- and nitro-phenylpyrrole compounds. The metabolites thus obtained were further purified by HPLC with varying methanol - water mixtures as eluents.

Chromatographic Purification and Identification

Accumulation and purification of the metabolites were monitored by thin-layer chromatography on Silica gel G/UV $\mathrm{U}_{254}$ (Macherey-Nagel) with either toluene or chloroform - acetic acid (95:5) as eluents (detection by UV/254 $\mathrm{nm}$ and by spraying with VAN URK's reagent ${ }^{8)}$ ).

The HPLC separations were performed on a HPLC apparatus (Knauer, Berlin, F.R.G.), equipped with a high-pressure pump and dual detector, with stainless-steel columns $(8 \mathrm{~mm} \times 250 \mathrm{~mm})$ filled with Lichrosorb RP8 $(5 \sim 20 \mu \mathrm{m})$.

Spectral Characterization

UV: Spektralphotometer DMR 21 (Zeiss, Oberkochen, F.R.G.); MS and GC-MS: mass spectrometer Varian 3700 (Varian, Bremen, F.R.G.), glass capillary columns, 25 m, SE 30; ${ }^{1}$ H NMR: Bruker WM 250 (Bruker, Karlsruhe-Forchheim, F.R.G.).

Chemical Reduction of Brominated Nitrophenylpyrrole Derivatives

The nitro compound $(510 \mu \mathrm{g})$ was dissolved in $30 \mu \mathrm{l}$ of methanol; first $5 \mu \mathrm{l}$ of aqueous ammonia $(2.5 \%)$ and then $10 \mu \mathrm{l}$ of a solution of $104 \mathrm{mg}$ sodium dithionite in $1 \mathrm{ml}$ deionized water were added. The mixture was kept at $70^{\circ} \mathrm{C}$ for 1 hour, and extracted with chloroform. The organic layer was evaporated to dryness, re-dissolved in methanol - water (60:40), and purified by HPLC as described.

Microbial Decarboxylation of 2-Carboxy-4-(2-amino-3-bromophenyl)pyrrole (X)

$P$. aureofaciens (mutant strain $\mathrm{ACN}$ ) was grown in the mineral salt medium without sodium bromide, harvested in the early stationary phase, and taken up aseptically in one-third the original volume of minimal medium. Approximately $500 \mu \mathrm{g}$ of $\mathbf{X}$ were added, and the fermentation was continued. After 4 days of incubation, the medium (including the cells) was extracted twice with 2 volumes of ethyl acetate, dried over anhydrous $\mathrm{MgSO}_{4}$, and evaporated to dryness in vacuo. The resulting product was re-dissolved in methanol - water (60:40), purified by HPLC, and identified by GC-MS and TLC.

Microbial Conversion of 4-(2-Amino-3-chlorophenyl)pyrrole (IV)

Compound IV was accumulated as described previously ${ }^{10)}$; incubation was continued after addition of sodium chloride to the medium, and metabolite formation was monitored by TLC.

\section{Results}

\section{Characterization of Brominated Pyrrolnitrin Derivatives}

The brominated phenylpyrrole compounds obtained from the fermentation extracts were purified by HPLC; details are given in Table 1 together with the TLC Rf values and the color reactions with VAN URK's reagent. The elemental composition of each compound was established by MS or GC-MS; mass and UV spectral data are collected in Table 2. The detailed structures of the isolated metabolites and the reference compounds pyrrolnitrin, aminopyrrolnitrin, and 4-(2-amino-3-chlorophenyl)pyrrole were analyzed by ${ }^{1} \mathrm{H}$ NMR (see below Table 3 ).

The isolated amino compounds displayed no biological activity; the nitro compounds, on the other hand, inhibited the growth of $N$. crassa. To obtain the same inhibition as shown with $10 \mu \mathrm{g} / \mathrm{ml}$ of pyrrolnitrin, $60 \mu \mathrm{g} / \mathrm{ml}$ of II, $266 \mu \mathrm{g} / \mathrm{ml}$ of $\mathbf{X}$, and $2,215 \mu \mathrm{g} / \mathrm{ml}$ of III were required.

Chemical and Microbial Interconversion of Metabolites

When 4-(3-bromo-2-nitrophenyl)pyrrole (XI) was reduced with sodium dithionite, the resulting 
Table 1. Purification of compounds by HPLC, Rf values for TLC and color reactions with VAN URK'S reagent.

\begin{tabular}{|c|c|c|c|c|}
\hline \multicolumn{2}{|l|}{ Compound } & $\mathrm{HPLC}^{\mathrm{a}}$ & \multirow{3}{*}{$\frac{\begin{array}{c}\mathrm{TLC}^{\mathrm{b})} \\
\text { eluent/Rf }\end{array}}{\mathrm{B} / 0.31}$} & \multirow{3}{*}{$\begin{array}{c}\begin{array}{c}\text { Color } \\
\text { reaction }\end{array} \\
\text { Orange }\end{array}$} \\
\hline 2-Carboxy-4-(2-amino-3-bromophenyl)pyrrole & $(\mathbf{X})$ & 1. $60: 40$ & & \\
\hline & & $\begin{array}{l}\text { 2. } \mathrm{MeOH}-\mathrm{H}_{2} \mathrm{O}-\mathrm{AcOH} \text {, } \\
50: 50: 1\end{array}$ & & \\
\hline \multirow[t]{2}{*}{ 4-(2-Amino-3-bromophenyl)pyrrole } & (VI) & 1. $60: 40$ & $\mathrm{~A} / 0.19$ & Olive green \\
\hline & & 2. $40: 50$ & & \\
\hline \multirow[t]{2}{*}{ 2-Bromo-4-(2-amino-3-bromophenyl)pyrrole } & (VII) & 1. $60: 40$ & $\mathrm{~A} / 0.32$ & Ochre \\
\hline & & 2. $60: 45$ & & \\
\hline \multirow[t]{2}{*}{ 3-Bromo-4-(2-amino-3-bromophenyl)pyrrole $\left.{ }^{\mathfrak{c}}\right)$} & (VIII) & 1. $60: 40$ & $\mathrm{~A} / 0.20$ & Orange \\
\hline & & 2. $50: 40$ & & \\
\hline \multirow{2}{*}{\multicolumn{2}{|c|}{ 2,3-Dibromo-4-(2-amino-3-bromophenyl)pyrrole (IX) }} & 1. $60: 40$ & $\mathrm{~A} / 0.21$ & Brown \\
\hline & & 2. $60: 45$ & & \\
\hline \multirow[t]{2}{*}{ 4-(2-Nitro-3-bromophenyl)pyrrole } & (XI) & 1. $60: 40$ & $\mathrm{~A} / 0.39$ & Blue \\
\hline & & 2. $50: 40$ & & \\
\hline \multirow[t]{2}{*}{ 3-Bromo-4-(2-nitro-3-bromophenyl)pyrrole } & (II) & 1. $60: 40$ & $\mathrm{~A} / 0.51$ & Blue \\
\hline & & 2. $50: 40$ & & \\
\hline 2,3-Dibromo-4-(2-nitro-3-bromophenyl)pyrrole & (III) & 1. $60: 40$ & A/0.56 & Violet \\
\hline
\end{tabular}

a) $\mathrm{RP} 8,5 \sim 20 \mu \mathrm{m}$; eluent $\mathrm{MeOH}-\mathrm{H}_{2} \mathrm{O}$.

b) Silica gel G/UV $\mathrm{UV}_{254}$; eluent $\mathrm{A}$ : toluene; eluent $\mathrm{B}$ : chloroform - $\mathrm{AcOH}(95: 5)$.

c) Obtained by reduction of II with $\mathrm{Na}_{2} \mathrm{~S}_{2} \mathrm{O}_{4}$.

Table 2. MS and UV spectroscopic data of the brominated pyrrolnitrin derivatives.

\begin{tabular}{|c|c|c|c|c|}
\hline \multirow{2}{*}{ Compound } & \multirow{2}{*}{$\begin{array}{l}\text { Mass spectra } \\
m / z \text { of significant ions (rela- } \\
\text { tive intensity as } \% \text { base peak) }\end{array}$} & \multicolumn{3}{|c|}{$\lambda_{\max }[\mathrm{nm}]($ in $\mathrm{MeOH}, \sim 10 \mu \mathrm{M})$} \\
\hline & & Neutral & Acidic $^{a)}$ & Alkaline $^{\text {a) }}$ \\
\hline \multirow[t]{3}{*}{$\mathrm{x}$} & $294 / 296(62)^{\mathrm{b})}$ & 305 & 296 & 305 \\
\hline & $262 / 264(100)$ & 261 & 274 & 261 \\
\hline & $155(91)$ & & & \\
\hline \multirow[t]{3}{*}{ VI } & $236 / 238(100)$ & 304 & 260 & 304 \\
\hline & 208/210 (50) & 260 & & 260 \\
\hline & $156(47)$ & & & \\
\hline \multirow[t]{4}{*}{ VII } & $314 / 316 / 318(13)$ & 305 & 300 & 305 \\
\hline & $235 / 237(30)$ & 267 & 270 & 267 \\
\hline & $208 / 210(15)$ & & & \\
\hline & $156(100)$ & & & \\
\hline \multirow[t]{4}{*}{ VIII } & $314 / 316 / 318(12)$ & 297 & 294 & 297 \\
\hline & 235/237 (34) & & & \\
\hline & 208/210 (6) & & & \\
\hline & $156(100)$ & & & \\
\hline \multirow[t]{4}{*}{ IX } & $392 / 394 / 396 / 398(10)$ & 303 & 300 & 303 \\
\hline & $313 / 315 / 317$ (39) & & & \\
\hline & $286 / 288 / 290(15)$ & & & \\
\hline & $234 / 236(82)$ & & & \\
\hline \multirow[t]{2}{*}{ XI } & 266/268 (35) & 282 & 278 & 282 \\
\hline & 239/241 (100) & 244 & 253 & 244 \\
\hline \multirow[t]{3}{*}{ II } & $344 / 346 / 348(11)$ & 248 & 248 & 248 \\
\hline & $316 / 318 / 320(12)$ & & & \\
\hline & $237 / 239(24)$ & & & \\
\hline \multirow[t]{2}{*}{ III } & $422 / 424 / 426 / 428(10)$ & 276 & 276 & 305 \\
\hline & 392/394/396/398 (4) & & & 281 \\
\hline
\end{tabular}

a) $0.1 \mathrm{ml}$ of $0.1 \mathrm{M} \mathrm{NaOH}$ or $\mathrm{HCl}$, respectively, added to $1 \mathrm{ml}$ of metabolite solution.

b) For the halogen multiplets, the intensity of the most abundant ion peak is given. 
Table 3. ${ }^{1} \mathrm{H}$ NMR data from numerical analysis $\left.{ }^{\mathrm{a}}\right)\left(\delta_{\mathrm{TMS}}(\mathrm{ppm}), J(\mathrm{~Hz})\right)$ of halogenated nitro- and aminophenylpyrrole compounds in both $\left(\mathrm{CD}_{3}\right)_{2} \mathrm{CO}$ and $\mathrm{CDCl}_{3}$ solution $\left(30^{\circ} \mathrm{C}\right)^{\mathrm{b})}$.

The different values in the two solvents for each compound are given as ..../. .

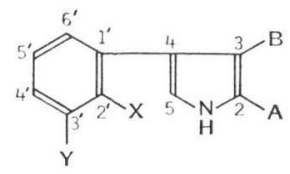

\begin{tabular}{|c|c|c|c|c|c|c|c|c|c|c|}
\hline Compound & I & II & III & $\left.I V^{c}\right)$ & $\mathbf{V}$ & $\left.V I^{c}\right)$ & VII & VIII & IX & $\mathbf{X}\left(\right.$ in $\left.\mathrm{CD}_{3} \mathrm{OD}\right)$ \\
\hline A & $\mathrm{H}$ & $\mathrm{H}$ & $\mathrm{Br}$ & $\mathrm{H}$ & $\mathrm{H}$ & $\mathrm{H}$ & $\mathrm{Br}$ & $\mathrm{H}$ & $\mathrm{Br}$ & $\mathrm{COOH}$ \\
\hline B & $\mathrm{Cl}$ & $\mathrm{Br}$ & $\mathrm{Br}$ & $\mathrm{H}$ & $\mathrm{Cl}$ & $\mathrm{H}$ & $\mathbf{H}$ & $\mathrm{Br}$ & $\mathrm{Br}$ & H \\
\hline $\mathrm{X}$ & $\mathrm{NO}_{2}$ & $\mathrm{NO}_{2}$ & $\mathrm{NO}_{2}$ & $\mathrm{NH}_{2}$ & $\mathrm{NH}_{2}$ & $\mathrm{NH}_{2}$ & $\mathrm{NH}_{2}$ & $\mathrm{NH}_{2}$ & $\mathrm{NH}_{2}$ & $\mathrm{NH}_{2}$ \\
\hline $\mathrm{Y}$ & $\mathrm{Cl}$ & $\mathrm{Br}$ & $\mathrm{Br}$ & $\mathrm{Cl}$ & $\mathrm{Cl}$ & $\mathrm{Br}$ & $\mathrm{Br}$ & $\mathrm{Br}$ & $\mathrm{Br}$ & $\mathrm{Br}$ \\
\hline $4^{\prime}-\mathrm{H}$ & $7.646 / 7.430$ & $7.791 / 7.592$ & $7.832 / 7.623$ & /7.167 & $7.190 / 7.239$ & $7.301 / 7.327$ & $7.301 / 7.339$ & 17.403 & $7.380 / 7.412$ & 7.279 \\
\hline $5^{\prime}-\mathrm{H}$ & $7.665 / 7.441$ & $7.588 / 7.373$ & $7.615 / 7.390$ & 16.695 & $6.662 / 6.716$ & $6.613 / 6.629$ & $6.568 / 6.618$ & $/ 6.648$ & $6.602 / 6.641$ & 6.590 \\
\hline $6^{\prime}-\mathrm{H}$ & $7.605 / 7.519$ & $7.615 / 7.543$ & $7.604 / 7.503$ & 17.132 & $7.044 / 7.091$ & $7.181 / 7.161$ & $7.121 / 7.089$ & 17.099 & $7.023 / 7.052$ & 7.120 \\
\hline${ }^{3} \boldsymbol{J}_{\left(4^{\prime}-\mathrm{H}, 5^{\prime}-\mathrm{H}\right)}$ & $8.17 / 8.11$ & $8.08 / 8.07$ & $8.16 / 8.08$ & 17.99 & $8.02 / 8.01$ & $8.01 / 8.01$ & $8.00 / 8.01$ & $/ 8.01$ & $8.02 / 8.05$ & 8.01 \\
\hline${ }^{4} J_{\left(4^{\prime}-\mathrm{H}, \theta^{\prime}-\mathrm{H}\right)}$ & $1.23 / 1.19$ & $1.24 / 1.23$ & $1.22 / 1.23$ & $/ 1.48$ & $1.51 / 1.52$ & $1.46 / 1.45$ & $1.53 / 1.51$ & $/ 1.51$ & $1.55 / 1.45$ & 1.45 \\
\hline${ }^{3} \boldsymbol{J}_{\left(5^{\prime}-H, \theta^{\prime}-H\right)}$ & $7.89 / 7.94$ & $7.84 / 7.88$ & $7.89 / 7.87$ & 17.60 & $7.57 / 7.54$ & $7.54 / 7.57$ & $7.54 / 7.57$ & $/ 7.57$ & $7.52 / 7.52$ & 7.58 \\
\hline $2-\mathrm{H}$ & $7.013 / 6.833$ & $7.045 / 6.876$ & & $/ 6.899$ & $6.985 / 6.888$ & $6.96^{\mathrm{d})} / 6.897$ & & $/ 6.935$ & & \\
\hline $3-\mathrm{H}$ & & & & 16.440 & & $6.37 / 6.429$ & $6.345 / 6.357$ & & & e) \\
\hline $5-\mathrm{H}$ & $6.901 / 6.815$ & $6.914 / 6.832$ & $7.028 / 6.871$ & 17.005 & $6.941 / 6.852$ & $7.08 / 6.994$ & $7.073 / 6.920$ & $/ 6.856$ & $7.059 / 6.885$ & e) \\
\hline${ }^{3} \boldsymbol{J}_{(2-\mathrm{H}, \mathrm{NH})}$ & $2.93 / 2.87$ & $2.87 / 2.80$ & & 12.73 & $2.90 / 2.89$ & d) $/ 2.72$ & & 12.87 & & \\
\hline${ }^{3} \boldsymbol{J}_{(2-\mathrm{H}, 3-\mathrm{H})}$ & & & & $/ 2.47$ & & $/ 2.75$ & & & & \\
\hline${ }^{4} J_{(2-\mathrm{H}, 5-\mathrm{H})}$ & $2.27 / 2.39$ & $2.20 / 2.29$ & & $/ 2.01$ & $2.29 / 2.36$ & $/ 2.05$ & & $/ 2.31$ & & \\
\hline${ }^{4} J_{(3-\mathrm{H}, \mathrm{NH})}$ & & & & $/ 2.67$ & & $/ 2.66$ & $2.64 / 2.68$ & & & e) \\
\hline${ }^{4} J_{(3-\mathrm{H}, 5-\mathrm{H})}$ & & & & $/ 1.61$ & & $/ 1.60$ & $1.83 / 1.83$ & & & e) \\
\hline${ }^{3} J_{(5-\mathrm{H}, \mathrm{NH})}$ & $3.23 / 3.28$ & $3.17 / 3.15$ & $/ 3.15$ & 12.64 & $3.09 / 3.01$ & 12.62 & $2.71 / 2.62$ & $/ 2.99$ & $3.03 / 3.08$ & e) \\
\hline
\end{tabular}

a) Pulsed Fourier transform spectra were measured at $250 \mathrm{MHz}$ nominal ${ }^{1} \mathrm{H}$ frequency. For the aryl and pyrrole spectra, spectral widths were selected between 500 and $600 \mathrm{~Hz}$, and 16k interferograms were sampled, corresponding to a digital resolution of $0.0145 \mathrm{~Hz}$ in the partial spectra. The values given for $\delta, J$ are taken from numerical analyses of the phenyl and pyrrole partial spectra (Nicolet program ITRCL1/2, NIC 17-30712).

b) Concentration of the metabolites in the sample solutions was always $<1 \mathrm{mg} / \mathrm{ml}$.

c) Correct nomenclature requires the numbering in the pyrrole ring of the compounds IV and VI to be reversed (e.g. 3-(2-amino-3-halophenyl)pyrrole); for ease of comparison, the same numbering is retained for all derivatives in Table 3 .

d) Numerical analyses not possible because of unresolved benzylic coupling and/or pyrrole $\mathrm{N}-\mathrm{H}$ coupling not completely removed by chemical exchange

e) Extremely broad signals due to intermediate $\mathrm{H}, \mathrm{H}$ exchange velocity. 
product was identified as the corresponding amino compound VI by HPLC (methanol - water, 45: 55), TLC (eluent toluene) and GC (comparison with an authentic sample from the fermentation). Compounds II and III were reduced to VIII and IX, respectively; VIII could not be isolated from either the culture medium or the cells.

The product from transformation of the pyrrolecarbonic acid (X) under resting cell conditions was identified as VI by HPLC, TLC, and GC-MS.

When sodium chloride was added to cultures containing accumulated $\mathbf{I V}$, compound $\mathbf{V}$ could be detected within 3 hours. After 23 hours, IV was totally converted into $\mathbf{V}$ (main product) and pyrrolnitrin (I).

\section{${ }^{1} \mathrm{H}$ NMR Spectral Analysis}

The relative position of the halogen substituents in the isolated metabolites, especially for the pyrrole ring, was deduced exclusively from ${ }^{1} \mathrm{H}$ NMR evidence. The individual structural assignments are therefore outlined in detail. To establish certain trends with successively higher halo substitution, a total analysis of all spectra was required. The chemical shift and coupling data for the new pyrrolnitrin derivatives and some reference compounds are given in Table 3. The values are derived from numerical analyses because extremely tight coupling prevents first order evaluation of the aryl proton region of some spectra even at $250 \mathrm{MHz}$.

In all compounds, the phenyl ring bears three substituents: a pyrrole ring, $\mathrm{Br}$ or $\mathrm{Cl}$, and $\mathrm{NH}_{2}$ or $\mathrm{NO}_{2}$. The three aryl protons occupy adjacent positions since each signal is split by ortho coupling $\left({ }^{3} J=7.5 \sim\right.$ $8.2 \mathrm{~Hz}$ ). However, especially for the $\mathrm{NO}_{2}$ derivatives, this is apparent only from the numerical analysis and not from the actual spectra. The 5'-protons which are coupled to two ortho neighbors, can be assigned straightforwardly. The triplet splitting pattern of this proton is shifted to significantly higher field by the $+\mathrm{M}$ effect of the $\mathrm{NH}_{2}$ group in compounds $\mathbf{I V} \sim \mathbf{X}$; this identifies the 2 '-substituent. Differentiation between the $4^{\prime}-$ and $6^{\prime}-\mathrm{H}$ resonances relies on the well-documented halogen shift increments for benzene derivatives ${ }^{11)}$. Since the phenyl substitution pattern is the same in the whole series, the increments should be similar in all spectra; the actual difference in the ortho increment observed between $\mathrm{Cl}$ and $\mathrm{Br}$ is small (see Table 3). The numerical values (from quantum mechanical calculations) show ${ }^{8} \boldsymbol{J}_{\left(4^{\prime}-\mathrm{H}, \mathrm{5}^{\prime}-\mathrm{H}\right)}$ to be invariably $0.2 \sim 0.5 \mathrm{~Hz}$ larger than ${ }^{8} \boldsymbol{J}_{\left(\mathrm{C}^{\prime}-\mathrm{H}, \mathrm{B}^{\prime}-\mathrm{H}\right)}$; thus, assignment of $4^{\prime}-$ and $6^{\prime}-$ resonances is possible even for almost identical chemical shifts. This $4^{\prime} / 6^{\prime}-\mathrm{H}$ differentiation is needed to distinguish between 2 - and 5 -halo substitution in the pyrrole ring (see below).

In a pyrrole nucleus, ortho $(2,5-\mathrm{H})$ and meta $(3,4-\mathrm{H})$ proton signals are always separated by $0.5 \sim$ $0.6 \mathrm{ppm}^{12)}$; the pyrrole proton data from the monobromo- and monochloroamino compounds VI and IV demonstrate that this also holds for the 4-phenyl derivatives. The dibromonitro metabolite II lacks the $6.4 \mathrm{ppm}$ signal, as does authentic pyrrolnitrin, i.e. the second halogen is in the 3-position. In assigning the two low field resonances of II, as well as of pyrrolnitrin, to 2- and 5- $\mathrm{H}$, respectively, we rely on an experiment described by CHANG et al. ${ }^{3)}$ : If pyrrolnitrin is specifically deuterated in the 2-position by decarboxylation of the corresponding 2-carboxylic acid in $\left[\mathrm{OH}-\mathrm{D}_{3}\right]$ glycerol, the residual pyrrole resonance, $6.86 \mathrm{ppm}$ in acetone- $d_{8}$, can be assigned unequivocally to $5-\mathrm{H}$, and the missing signal at 6.96 ppm to 2-H (both resonances are shifted to slightly lower field in our highly dilute solutions, see Table 3). In $\mathrm{CDCl}_{3}$, pyrrolnitrin displays almost identical 2- and 5-H shifts; a straightforward assignment is possible, though, on the basis of the respective, unequal ${ }^{3} \mathrm{~J}$ coupling to the $\mathrm{N}-\mathrm{H}$ proton since these ${ }^{3} \boldsymbol{J}_{(\mathrm{C}-\mathrm{H}, \mathrm{N}-\mathrm{H})}$ values are virtually identical in the two solvents used (see Table 3 ). In differentiating be- 
tween 2- and 5-H resonances of the dibromonitro metabolite $\mathbf{I}$, this coupling constant criterion is again applied, together with the fact that one expects little response in $\delta(5-\mathrm{H})$ to a change of the 3-halo substituent. Surprisingly, $\delta(2-\mathrm{H})$ likewise remains almost unchanged. The additional bromine in the tribromonitro compound III is assigned to the 2-position; a substituent in 5-position (ortho to the biaryl linkage) should strongly influence the 6 '- $\mathrm{H}$ signal in the ortho-position of the phenyl ring.

Unlike aminopyrrolnitrin (V), which was prepared by chemical reduction of authentic pyrrolnitrin (I) and thus is 3-chloro substituted, the dibromoamino compound VII produced by fermentation is unsubstituted in the 3-position. The $6.34 \mathrm{ppm}$ signal exhibits two couplings of 2.7 and $1.8 \mathrm{~Hz}$, respectively; the smaller of these values must be assigned to ${ }^{4} J_{(3-\mathrm{H}, 5-\mathrm{H})}$ (pyrrole: $1.3 \mathrm{~Hz}^{12)}$ ). If the heterocyclic bromo substituent were in the 5-position, the $3-\mathrm{H}$ signal would be split by ${ }^{3} J_{(2-\mathrm{H}, 3-\mathrm{H})}$ and ${ }^{4} J_{(3-\mathrm{H}, \mathrm{N}-\mathrm{H})}$, both of which should be larger than $2.5 \mathrm{~Hz}^{13)}$. The $1.6 \mathrm{~Hz}$ value for this ${ }^{4} J_{(3-\mathrm{H}, 5-\mathrm{H})}$ long range coupling in the monochloro- and monobromoamino compounds, by far the smallest of all coupling constants of IV and VI, allows a definite assignment of their 5-H resonances (see Table 3 ).

The dibromoamino derivative VIII, prepared by chemical reduction of $\mathbf{I I}$, lacks the high field (i.e. 3-H) pyrrole resonance. The tribromoamino metabolite IX, where this signal is likewise missing, consequently has one $\mathrm{Br}$ in 3-position; the second bromine must be assigned to the 2-position since the phenyl proton resonances of IX are practically identical with those of VIII. The 5-H resonance of VIII is assigned by analogy with that of IX $(\Delta \delta-0.03 \mathrm{ppm})$ : almost the same $5-\mathrm{H}$ shift difference $(-0.04 \mathrm{ppm})$ is observed between the di- and tribromonitro derivatives $\mathbf{I I}$ and III. Finally the resonances of aminopyrrolnitrin are assigned by comparison of the $\delta$ - and $J$-values with those of the bromo analogue VIII.

The marked low field shift of the 3-H signal in the bromoaminophenylpyrrole carbonic acid (X), in conjunction with the again unchanged phenyl proton shifts, is clear proof that the $\mathrm{COOH}$ function is in the 2-position of the pyrrole ring.

\section{Discussion}

The biosynthesis of pyrrolnitrin (I) incorporates several halogenation steps. The chloroperoxidase system by which tryptophan is converted to pyrrolnitrin in $P$. aureofaciens was thought to be highly specific for chloride ${ }^{4}$, in sharp contrast to the chloroperoxidase reported in the case of caldariomycin ${ }^{14)}$. In 1969, however, AJISAKA et al..$^{5)}$ isolated three brominated nitrophenylpyrrole compounds from several Pseudomonas species. It seemed unlikely that the chloroperoxidases of these strains should be less specific than that of $P$. aureofaciens. The isolation of tribromo derivatives of both amino- and nitrophenylpyrrole (IX, III), described in this paper, indeed suggests that the $P$. aureofaciens chloroperoxidase is probably even more active with bromide than with chloride.

The formation and isolation of 2-bromo-4-(2-amino-3-bromophenyl)pyrrole (VII) shows that bromination is more selective than chlorination. The corresponding 3-bromopyrrole isomer VIII could not be isolated; due probably to rapid further bromination to IX or oxidation to II. Apart from this, the pathways for the formation of bromopyrrolnitrin (Scheme 1) and for pyrrolnitrin seem to be identical.

The conversion of 2-carboxy-4-(2-amino-3-bromophenyl)pyrrole (X) to VI and the conversion of the chloro analogue of VI to aminopyrrolnitrin (V) and pyrrolnitrin (I) establish that $\mathbf{X}$ and its chlorophenyl analogue are in fact intermediates in the biosynthesis of bromopyrrolnitrin and pyrrolnitrin, respectively starting from D-tryptophan (though not from L-tryptophan $\left.{ }^{3}\right)$ ). The fact that, in the absence of chloride, no phenylpyrrole moiety is produced from D-tryptophan, whereas 7-chlorotryptophan is smoothly transformed into 4-(2-amino-3-chlorophenyl)pyrrole (IV), suggests halogenation of tryptophan as the first step in pyrrolnitrin biosynthesis. Formation of the phenylpyrrole system is the next, halide-independent step. 
Scheme 1. Hypothetical pathway for the biosynthesis of brominated pyrrolnitrin derivatives (compounds enclosed in square brackets could not be isolated).

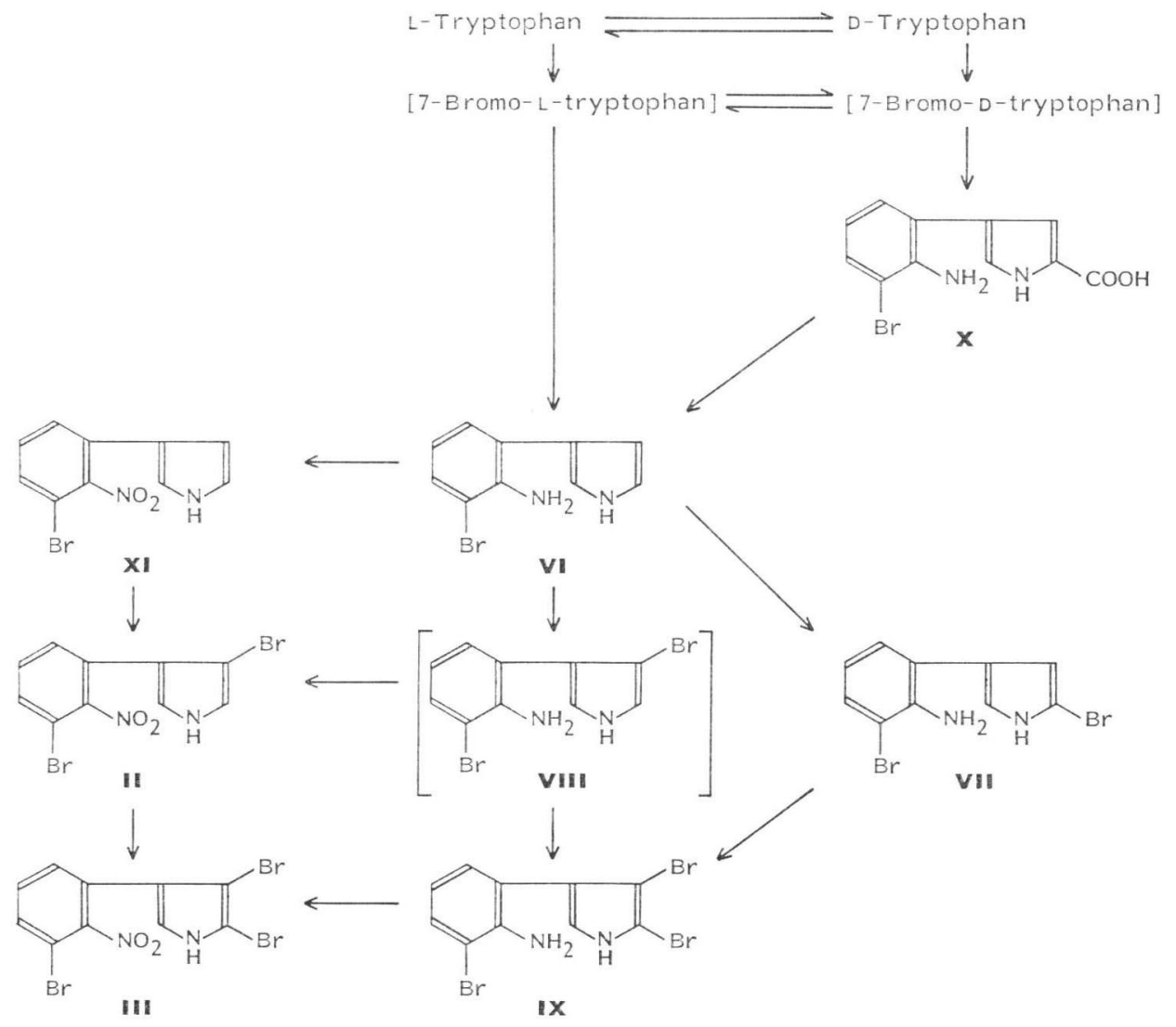

\section{References}

1) Arima, K. ; H. Imanaka, M. Kousaka, A. Fukuda \& G. Tamura: Pyrrolnitrin, a new antibiotic substance, produced by Pseudomonas. Agric. Biol. Chem. 28: 575 576, 1964

2) Elander, R. P.; J. A. Mabe, R. H. Hamill \& M. Gorman: Metabolism of tryptophans by Pseudomonas aureofaciens. Appl. Microbiol. 16: 753 758, 1968

3) Chang, C. J.; H. G. Floss, D. J. Hook, J. A. Mabe, P. E. Manni, L. L. Martin, K. Schröder \& T. L. SHIEH: The biosynthesis of the antibiotic pyrrolnitrin by Pseudomonas aureofaciens. J. Antibiotics 34: $555 \sim 566,1981$

4) Hamill, R.; R. Elander, J. Mabe \& M. Gorman: Metabolism of tryptophans by Pseudomonas aureofaciens. V. Conversion of tryptophan to pyrrolnitrin. Antimicrob. Agents Chemother. -1967: 338 396, 1968

5) Ajisaka, M.; K. Kariyone, K. Jomon, H. Yagawa \& K. Arima: Isolation of the bromo analogues of pyrrolnitrin. Agric. Biol. Chem. 33: 294 295, 1969

6) Salcher, O.; F. Lingens \& P. Fischer: Biosynthese von Pyrrolnitrin - Nachweis von 4-(2'-Amino-3'chlorphenyl)pyrrol-2-carbonsäure. Tetrahedron Lett. 1978: 3097 3100, 1978

7) SALCHER, O.\& F. Lingens: Isolation and characterisation of a mutant of Pseudomonas aureofaciens ATCC 15926 with an increased capacity for synthesis of pyrrolnitrin. J. Gen. Microbiol. 118: 509 513, 1980

8) Gordee, R. S. \& J. Westhead: Pyrrolnitrin. Anal. Microbiol. 2: 329 338, 1972

9) Stahl, E. \& H. Kaldewey: Spurenanalyse physiologisch aktiver, einfacher Indolderivate. Hoppe-Seyler's Z. Physiol. Chem. 323: 182 191, 1961

10) VAN PÉE, K.-H.; O. SAlcher \& F. Lingens: Formation of pyrrolnitrin and 3-(2-amino-3-chlorophenyl)pyrrole from 7-chlorotryptophan. Angew. Chemie, Int. Ed. Engl. 19: 828 829, 1980 
11) Jackman, L. M. \& S. Sternhell: Applications of Nuclear Magnetic Resonance Spectroscopy in Organic Chemistry. 2nd ed., pp. 202 215, Pergamon Press, New York, 1969

12) Batterham, T. J.: NMR Spectra of Simple Heterocycles. Wiley, New York, 1973

13) Dischler, B.: Analyse kernmagnetischer Resonanzspektren vom Typ $\mathrm{A}_{2} \mathrm{~B}_{2}$ mit Ergebnissen von paradisubstituierten Benzolen, Äthylengruppen und Pyrrol. Z. Naturforsch. 20 a: 888 901, 1965

14) Patterson, E. L.; W. W. Andres \& L. A. Mitcher: Isolation of the bromo analogue of caldariomycin from Caldariomyces fumago. Appl. Microbiol. 15: 528 530, 1967 